\title{
Przekształcenie relacji występujących w hasłach rozwiniętych i opisach przedmiotowych KABA do postaci powiązań w mapie tematów
}

\author{
Bartłomiej Włodarczyk \\ Katedra Bibliografii i Dokumentacji, \\ Wydziat Dziennikarstwa, Informacji i Bibliologii, Uniwersytet Warszawski
}

\begin{abstract}
Abstrakt
Cel/teza: Celem artykułu jest wskazanie możliwości i problemów transformacji wybranych haseł rozwiniętych KABA do postaci powiązań w mapie tematów opartej na JHP KABA.

Koncepcja/metody badań: Na podstawie analizy dokumentacji opublikowanej na stronie Centrum NUKAT przeprowadzono ocenę możliwości wprowadzenia bardziej szczegółowej kategoryzacji jednostek leksykalnych języka KABA. Następnie analizując noty stosowania określników rzeczowych, wskazano na rodzaje konstrukcji występujących we wspomnianym języku oraz możliwości ich przekształcenia w powiązania w mapie tematów.

Wyniki i wnioski: W języku KABA, oprócz podziału tematów i określników zgodnego z etykietami pól formatu MARC 21 dokonano kategoryzacji określników w celu kontroli połączeń między jednostkami leksykalnymi w hasłach rozwiniętych. Dane na ten temat są zapisane w rekordach wzorcowych określników (pole 073). Brakuje ich jednak w rekordach wzorcowych tematów (pole 072), co uniemożliwia automatyczną kontrolę poprawności haseł. Pokazano, że ich uzupełnienie tylko w ograniczonym zakresie może być pomocne przy przekształcaniu języka do postaci mapy tematów. W przypadku niektórych jednostek identyfikujących argumenty relacji konieczne było zaproponowanie dodatkowych kategorii, które pozwoliły na zapis ograniczeń dotyczących powiązań. W artykule zaprezentowano przykłady przekształcenia wybranych haseł i opisów przedmiotowych. Kryterium doboru było występowanie w ich składzie określników rzeczowych reprezentujących relacje między przedmiotami. Podział całości zasobu leksykalnego KABA byłby dużo bardziej złożony i wymagałby utworzenia licznych ograniczeń. Zalecane byłoby przynajmniej częściowe zautomatyzowanie tej pracy.

Oryginalność/wartość poznawcza: W artykule zaprezentowano propozycję przekształcenia relacji występujących w hasłach rozwiniętych i w opisach przedmiotowych KABA w mapę tematów. Przedstawiona propozycja $\mathrm{z}$ jednej strony wypełnia w pewnym stopniu lukę, jaka istnieje w tym zakresie w literaturze z zakresu informatologii. $Z$ drugiej strony jest ona głosem w dyskusji na temat przyszłości języków haseł przedmiotowych, w szczególności JHP KABA, pokazując rozwiązanie wpisujące się w nurt współczesnych projektów semantycznych. W związku z kompatybilnością języka KABA z językami RAMEAU i LCSH, rezultaty badań mogą być częściowo zastosowane odnośnie do tych narzędzi.
\end{abstract}

\section{Słowa kluczowe}

Hasła rozwinięte. Język haseł przedmiotowych KABA. Mapy tematów. Relacje.

Otrzymany: 17 czerwca 2016. Z Zrecenzowany: 6 lipca 2016. Zatwierdzony: 1 sierpnia 2016. 


\section{Wprowadzenie}

W katalogach polskich bibliotek obecnie są wykorzystywane głównie dwa języki haseł przedmiotowych (JHP): Język Haseł Przedmiotowych KABA (Katalogów Automatycznych Bibliotek Akademickich, JHP KABA) oraz Język Haseł Przedmiotowych Biblioteki Narodowej (JHP BN). Pierwszy z nich jest stosowany w sieci bibliotek naukowych i akademickich współpracujących w ramach Narodowego Uniwersalnego Katalogu Centralnego (NUKAT), drugi zaś w Bibliotece Narodowej (BN) oraz w większości bibliotek publicznych.

W BN trwają prace nad przekształceniem JHP BN w Deskryptory Biblioteki Narodowej (DBN). Zgodnie z założeniami projektu, JHP o prekoordynowanych jednostkach leksykalnych, ma zostać przekształcony w język deskryptorowy, w którym „gramatykę stanowią najczęściej reguły indeksowania współrzędnego" (Jezyk deskryptorowy, 2002). Wśród przyczyn podjęcia decyzji o przekształceniu rozwijanego od 1957 r. języka wymieniono m.in. jego niedostosowanie do wymagań współczesnych systemów informacyjno-wyszukiwawczych, w tym wyszukiwania fasetowego (Cichoń et al., 2014, 174-177). W związku z przemianami zachowań informacyjnych użytkowników oraz rozwojem systemów informacyjno-wyszukiwawczych, również twórcy drugiego polskiego JHP stoją obecnie przed koniecznością podjęcia decyzji dotyczącej jego przyszłości. Jednym z rozwiązań jest całkowita fasetyzacja struktury języka, a więc przyjęcie modelu transformacji podobnego do rozwiązania opracowywanego obecnie w BN. Ostateczna decyzja powinna uwzględniać potrzeby informacyjne użytkowników, które w projekcie przekształcenia powinny być traktowane priorytetowo, a także możliwości bibliotek współpracujących w ramach NUKAT. W propozycji przekształcenia należy wziąć pod uwagę specyficzne cechy języka KABA.

Celem artykułu jest wskazanie odmiennej możliwości transformacji JHP KABA, tj. transformacji haseł rozwiniętych KABA w sieć powiązań w mapie tematów (ang. topic map). Propozycję przekształcenia JHP BN zgodnie z tym wzorcem przedstawiono w osobnej publikacji (Włodarczyk, 2016). Mapy tematów są standardem reprezentacji wiedzy, którego model zakłada istnienie „tematów” (ang. topics), reprezentujących różne pojęcia i obiekty (tzw. przedmioty), „powiązań” (ang. associations), czyli relacji łączących tematy, oraz „wystąpień” (ang. occurrences), będących relacjami między tematami a relewantnymi zasobami informacyjnymi. Element „zakres” (ang. scope) reprezentuje kontekst, w którym ważne są m.in. powiązania. W artykule standard map tematów (ISO, 2006) traktowany jest jako podstawa przekształcenia haseł rozwiniętych KABA. Hasło rozwinięte można potraktować jako zbiór jednostek połączonych różnymi rodzajami relacji. W JHP jednymi z najpowszechniej wykorzystywanych związków na poziomie syntagmatycznym są relacje łączące przedmiot dokumentu z jego lokalizacją przestrzenną i czasową. Te dwa podstawowe rodzaje relacji nie wyczerpują jednak katalogu związków występujących w hasłach rozwiniętych. Na pozostałe wskazują niektóre określniki rzeczowe oraz formy. Ponadto, relacje między różnymi przedmiotami są zawarte w ramach tematów ogólnych. Dotyczy to niektórych tematów składających się z elementów połączonych spójnikiem „i”, np. „Religia i państwo”. W artykule poddano analizie jedynie określniki rzeczowe KABA wskazujące na związki między przedmiotami. Obiektem badań były zarówno rekordy wzorcowe tematów, określników i haseł rozwiniętych KABA, jak i rekordy bibliograficzne dostępne w tym katalogu. Przedstawione w artykule wyniki mogą posłużyć jako jeden z elementów przekształcenia języka KABA w system organizacji wiedzy (SOW) uwzględniający formalną specyfikację relacji między pojęciami. 
Zawartość artykułu została podzielona na trzy części. W pierwszej omówiono kategoryzację jednostek leksykalnych KABA. Zwrócono uwagę na możliwość formalizacji połączeń poszczególnych kategorii tematów z określnikami rzeczowymi. W drugiej części przedstawiono możliwości specyfikacji relacji zawartych w wybranych hasłach rozwiniętych KABA. Nie uwzględniono tematów, które identyfikują związki między przedmiotami. Zaprezentowano przykłady transformacji haseł zwierających wybrane określniki, wskazujące na relacje między przedmiotami, do postaci powiązań w mapie tematów. W trzeciej części przedstawiono sposób kontroli typów ról i tematów w powiązaniach. W zakończeniu zaprezentowano podsumowanie problematyki przedstawionej w artykule.

\section{Kategoryzacja jednostek leksykalnych KABA}

Rekordy wzorcowe języka KABA są zapisywane w formacie MAchine-Readable Cataloging 21 (MARC 21). Format ten zawiera odrębne pola służące do zapisu różnych rodzajów tematów - osobowego, korporatywnego dla tzw. ciał zbiorowych, korporatywnego dla tzw. imprez, tytułowego, ogólnego, geograficznego oraz formalnego. W formacie MARC 21 uwzględniono również podpola służące do zapisu określników, drugiej obok tematów kategorii leksykalnej JHP. Wyodrębniono podpola dla określników: rzeczowego, geograficznego, chronologicznego oraz formy. Podkategorie wyróżnione w ramach dwóch podstawowych kategorii leksykalnych JHP służą organizacji oraz kontroli słownictwa JHP. Są one jednak na tyle ogólne, że możliwości ich wykorzystania w procesie transformacji JHP do postaci SOW opartego na sieci jawnie specyfikowanych relacji są ograniczone.

W KABA, podobnie jak w Répertoire d'autorité matière encyclopédique et alphabétique unifié (RAMEAU) (BnF, 2016), ustanowiono dziedzinowe listy określników. Jednak nie wszystkie kategorie (listy) KABA występują we francuskim JHP. W NUKAT wyodrębniono osobną listę określników stosowanych po nazwach obozów i więzień (Ćwikowski, 2013, 80). Na stronie internetowej NUKAT napisano, że listy są „narzędziem ułatwiającym stosowanie określników w hasłach przedmiotowych rozwiniętych” (NUKAT-a, b.d.). Obecnie udostępniono następujące listy określników:
(1) Lista podstawowa (ORZF)
(15) Muzyka
(2) Choroby
(16) Nazwy geograficzne
(3) Ciała niebieskie
(17) Nazwy osobowe
(4) Ciała zbiorowe (CZB)
(18) Obozy i więzienia (OBW)
(5) Czasopisma
(19) Organizmy żywe
(6) Części ciała
(20) Parlamenty
(7) Dyscypliny sportowe
(21) Pojazdy
(8) Działy gospodarki (GOSP)
(22) Prawo
(9) Grupy etniczne
(23) Produkty i materiały
(10) Instrumenty muzyczne
(24) Religie
(11) Języki
(25) Siły zbrojne
(12) Kategorie osób
(26) Substancje chemiczne
(13) Księgi święte
(27) Tytuły dzieł
(14) Literatury
(28) Wojny 
Dla każdej listy określono rodzaje tematów, które można stosować w połączeniu z zawartymi na niej określnikami. Na liście podstawowej wymieniono określniki stosowane po różnych rodzajach tematów. Na pozostałych określono dokładnie, po jakich rodzajach tematów mogą być stosowane. Na przykład, na liście „Działy gospodarki” zapisano, że występujące na niej określniki stosuje się po „nazwach działów gospodarki, np.: Przemysł budowlany” oraz po „typach działalności gospodarczej i handlowej, np.: Centra handlowe”. W opisie tej listy zaznaczono również, że określników z tego wykazu nie „stosuje się po haśle Przemysł" (NUKAT-c, b.d.). Podobne uwagi znajdują się przy wszystkich listach określników zamieszczonych na stronie internetowej NUKAT. Informacje te, zapisane w rekordach wzorcowych, mogłyby posłużyć do automatycznej kontroli poprawności haseł rozwiniętych. Potencjalnie, ich zapisanie w rekordach wzorcowych mogłoby być także podstawą przekształcenia KABA, co zostanie przedstawione w dalszej części artykułu.

Do formalizacji zasad łączliwości określników z tematami mogą posłużyć pola 072 i 073 formatu MARC 21. Przykłady ich wykorzystania w Medical Subject Headings (MeSH) zaprezentowano na stronie Biblioteki Kongresu (BK) poświęconej wspomnianemu formatowi. W pierwszym z wymienionych pól można zamieścić kod kategorii, do której przypisano dany temat lub deskryptor, w drugim natomiast informacje na temat kategorii tematów lub deskryptorów, po których można stosować dany określnik lub modyfikator. Poniżej zamieszczono przykład użycia obu pól wraz z objaśnieniem zamieszczonym w dokumentacji formatu MARC 21 (LoC, 1999).

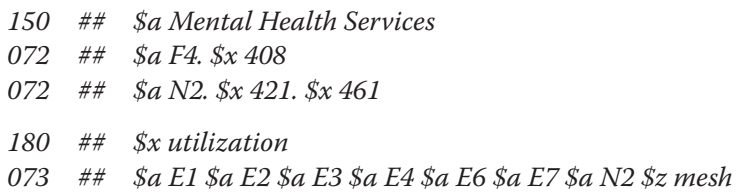

W rekordzie modyfikatora „utilization” (wykorzystanie) w powtarzalnym podpolu \$a pola 073 zamieszczono oznaczenia siedmiu kategorii deskryptorów, po których może on być stosowany. W podpolu \$z wskazano źródło słownictwa, czyli MeSH. W rekordzie deskryptora „Mental Health Services” (Opieka psychiatryczna) w podpolu \$a pola 072 zapisano kategorie, do których należy ta jednostka leksykalna. Dokładne umiejscowienie deskryptora w hierarchii zostało przedstawione w podpolach $\$ \mathrm{x} . \mathrm{Z}$ zapisu wynika, że deskryptor ten należy do kategorii F4 (Dyscypliny i działania behawioralne) oraz N2 (Zakłady opieki zdrowotnej, służba zdrowia i usługi zdrowotne). Modyfikator „utilization” można stosować po drugiej z wymienionych kategorii deskryptorów, a zatem jego połączenie z deskryptorem „Mental Health Services” jest zgodne z metodyką tworzenia haseł MeSH (LoC, 1999).

W Library of Congress Subject Headings (LCSH) wyróżniono 34 kategorie tematów. Kody dla tych kategorii do niedawna były zapisywane wyłącznie w polu 073 rekordów wzorcowych określników. W BK jest obecnie prowadzony projekt polegający na dodaniu odpowiednich kodów do wybranych rekordów wzorcowych tematów (pole 072). Autorzy tego przedsięwzięcia oczekują, że umożliwi to (LoC, 2012):

(1) zwiększenie użyteczności LCSH w środowisku Sieci Semantycznej,

(2) dostarczenie osobom katalogującym podpowiedzi poprzez udostępnienie listy określników, które można zastosować po danym temacie,

(3) automatyczne tworzenie i walidację haseł rozwiniętych LCSH. 
Poniżej zamieszczono przykład zastosowania pól 072 i 073 w rekordach LCSH (LoC, b.d.; LoC, 2016, 10).

$\begin{array}{ll}072 \# 7 & \text { \$a H } 1195 \$ 2 \text { lcsh } \\ 150 \# \# & \text { \$a Mazda } 6 \text { automobile } \\ 073 \# \# & \text { \$a H } 1195 \$ \text { lcsh } \\ 180 \# \# & \$ x \text { Bumpers } \\ 680 \# \# & \text { \$i Use as a topical subdivision under individual land vehicles and types of land vehicles. }\end{array}$

Obecnie sytuacja w języku KABA jest podobna do tej w LCSH sprzed rozpoczęcia wspomnianego projektu. Informacje o łączliwości poszczególnych określników KABA z tematami są wyłącznie częścią rekordów wzorcowych określników tego języka (pole 073). W rekordach wzorcowych tematów nie są uwzględnione informacje na temat ich przynależności kategorialnej (pole 072). Tym samym nie jest możliwa automatyczna kontrola poprawności haseł rozwiniętych. Jak podkreślono powyżej, najszerszy zakres zastosowania mają określniki zamieszczone na liście podstawowej. Część z nich można używać po wszystkich rodzajach tematów, np. określnik „analiza i indeksowanie dokumentów”, który „stosuje się po nazwach pospolitych i własnych do prac dotyczących analizy dokumentów z dziedziny określonej przez temat". W ich przypadku kontrola wydaje się zbędna ze względu na uniwersalne zastosowanie. Inne określniki z tej listy mają jednak o wiele węższy zakres stosowania. Przykładowo, określnik „aparatura i sprzęt” „stosuje się po nazwach instytucji i organizacji, gałęzi gospodarki, obozów i więzień oraz po właściwych nazwach przedmiotów (dziedzin, procesów technologicznych, itp.)”. Informacje te są uwzględnione w rekordzie wzorcowym określnika:

073 \#\# $\$ a$ CZB \$a GOSP \$a OBW \$a ORZF

180 \#\# \$x aparatura i sprzęt.

W celu zapewnienia pełnej kontroli poprawności haseł należałoby doprecyzować granice kategorii opisanej ogólnie jako „właściwe nazwy pospolite”. Wspomniano o braku informacji zapisywanych w polu 072 rekordów wzorcowych tematów KABA. W pełni automatyczne, szybkie dodanie tych danych jest obecnie możliwe dla tematów osobowych poprzez wykorzystanie etykiety 100 formatu MARC 21. Istnieje osobna lista określników stosowanych po nazwach osób, rodów, rodzin i dynastii. W przypadku innych kategorii tematów podpowiedź mogą stanowić ich etykiety oraz znajomość ich budowy, np. wszystkie tematy identyfikujące księgi biblijne rozpoczynają się od słowa „Biblia”, a jednostki identyfikujące języki od słów „Język” bądź „Języki”. Potencjalnie znaczenie mogą mieć również relacje hierarchiczne między tematami. Jednak w tym przypadku część tematów może zostać zaliczona do błędnej kategorii, np. przyjęcie, że wszystkie tematy KABA węższe znaczeniowo w stosunku do hasła „Biblioteki - personel” przynależą do klasy „Kategorie osób” spowoduje zaliczenie do niej m.in. tematu „Duszpasterstwo bibliotekarzy”. Uwzględnienia wymagają wyjątki zapisane na listach, np. określniki z listy „Ciała zbiorowe” nie są stosowane po nazwach różnego rodzaju obozów i więzień, dla których utworzono osobną listę (NUKAT-b, b.d.).

Istotnym zagadnieniem jest możliwość wykorzystania połączeń między określnikami a tematami w procesie przekształcania języka KABA w mapę tematów. Po uzupełnieniu rekordów wzorcowych tematów KABA o pola 072, uzyskane połączenia między tematami 
a określnikami miałyby postać par jednakowych oznaczeń, np. „nazwy osobowe” - „nazwy osobowe”. Informacje te nie są wystarczające do zapisu ograniczeń w mapie tematów, nie wskazują bowiem kategorii, do których należą pojęcia reprezentowane przez określniki bądź ich elementy odpowiadające argumentom relacji. Niezbędne jest wyodrębnienie kategorii, do których przynależą.

\section{Określniki rzeczowe KABA jako podstawa powiązań w mapie tematów - analiza wybranych przykładów}

W języku KABA, podobnie jak w JHP BN, istnieje możliwość wyszczególnienia relacji między jednostkami leksykalnymi wchodzącymi w skład jednego hasła bądź też całego opisu przedmiotowego. W mapie tematów pojedyncze tematy oraz tematy połączone powiązaniami mogą posłużyć do opisu treści lub formy dokumentów. W celu reprezentacji powiązań w postaci odrębnych tematów należałoby zastosować reifikację. W mapach tematów tylko tematy mogą być połączone powiązaniami lub wystąpieniami z opracowywanymi dokumentami. Poniżej zamieszczono rysunek (Rys. 1) prezentujący zastosowanie reifikacji w stosunku do powiązania. Powstały temat może zostać połączony z dokumentem bądź jego reprezentacją.

Rysunek 1. Zastosowanie reifikacji w celu stworzenia tematu służącego do opisu treści dokumentu.

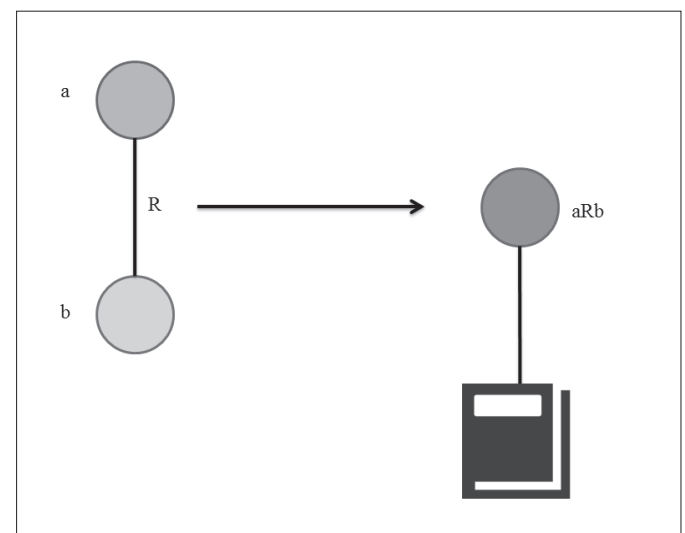

Źródło: opracowanie własne z wykorzystaniem „Book” by ANS (http://aiconica.net/books). CC0 1.0 Universal.

W tej części artykułu zostaną omówione możliwości przekształcenia wybranych haseł i całych opisów przedmiotowych, zawierających wybrane określniki KABA do postaci powiązań w mapie tematów. Wybrane jako przykłady określniki rzeczowe identyfikują relacje między przedmiotami. Uwzględnione zostaną wyłącznie hasła i opisy, w których wszystkie argumenty relacji są zapisane w sposób jawny. W przykładach pominięto lokalizację przestrzenną i czasową przedmiotów.

Pierwszy określnik - „stosunki wojskowe”, stosuje się w celu opisania polityki wojskowej jednego kraju wobec drugiego lub wobec grupy państw. Użycie określnika geograficznego po określniku „stosunki wojskowe” wskazuje na kraj lub region odniesienia. Zgodnie 
z pragmatyką JHP KABA należy zawsze utworzyć drugie hasło zaczynające się od nazwy występującej w określniku geograficznym . Relacja ta jest związkiem symetrycznym. Schemat prezentujący sposób zastosowania określnika w opisie przedmiotowym oraz przykład opisu zawierającego omawiany określnik zaprezentowano poniżej. Oznaczenie „a” identyfikuje pierwszy człon relacji, oznaczenie „R” określnik wskazujący na rodzaj relacji, a oznaczenie „b” jednostkę identyfikującą drugi człon relacji.

$a R b \quad 651$ \#\# \$a Finlandia \$x stosunki wojskowe \$z Polska

bRa 651 \#\# \$a Polska \$x stosunki wojskowe \$z Finlandia

W oparciu o hasła zawierające ten określnik można utworzyć powiązanie typu „państwo-pozostające-w-stosunkach-wojskowych/państwo-pozostające-w-stosunkach-wojskowych”, w którym powinny wystąpić dwa tematy pełniące rolę typu „państwo-pozostające-w-stosunkach-wojskowych”. Poniżej zaprezentowano zapis ograniczenia dotyczącego tego powiązania w języku ograniczeń map tematów - Topic Maps Constraint Language (TMCL) (ISO, 2011). Zgodnie z tym zapisem "państwo-pozostające-w-stosunkach-wojskowych/ państwo-pozostające-w stosunkach-wojskowych" jest typem powiązania zawierającym dokładnie dwie role typu „państwo-pozostające-w-stosunkach-wojskowych”.

państwo-pozostające-w-stosunkach-wojskowych/państwo-pozostające-w-stosunkach-wojskowych isa tmcl:association-type;

has-role(państwo-pozostające-w-stosunkach-wojskowych, 2, 2).

Poniżej przedstawiono przykład konkretnego powiązania tego typu.

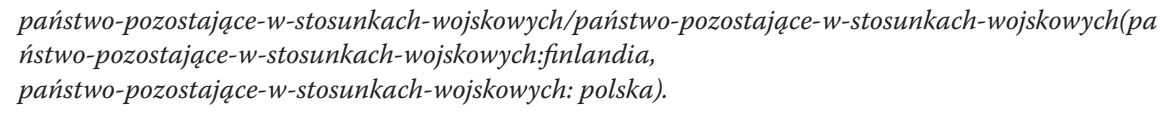

Należy podkreślić, że w języku KABA występują również hasła rozwinięte zawierające określnik „stosunki wojskowe”, ale bez następującego po nim określnika geograficznego. Hasła takie wskazują na sytuację, w której omawiane są ogólne stosunki wojskowe z różnymi krajami.

\section{1 \#\# \$a Polska \$x stosunki wojskowe}

W przedstawionym wyżej przykładzie można zazwyczaj wskazać drugi człon relacji, jednak z różną precyzją. Potencjalnie dokument na temat stosunków wojskowych z wieloma państwami można opracować, dodając jako drugi argument relacji temat „Świat”. Obecnie w KABA nazwa ta nie występuje w funkcji określnika. Przypadki te wymagają jeszcze dalszej analizy. W artykule wskazano na hasła lub opisy przedmiotowe, w których wszystkie argumenty relacji są zapisane w sposób jawny.

Nieco inaczej należy postąpić z określnikiem „gramatyka porównawcza", który może być stosowany po nazwach języków i grup języków samodzielnie bądź z dodatkiem drugiego określnika rzeczowego, wskazującego na „język będący obiektem badań komparatystycznych". Określnik ten identyfikuje relację porównania języków z punktu widzenia ich gramatyki. Podobnie jak w przypadku wyżej omówionego określnika, należy zawsze utworzyć dwa hasła. Schemat budowy opisu jest więc identyczny jak w przypadku określnika „stosunki wojskowe”. Przykład zastosowania określnika „gramatyka porównawcza” podano poniżej. 
650 \#\# \$a Jezzk litewski \$x gramatyka porównawcza \$x język polski

650 \#\# \$a Jęzk polski \$x gramatyka porównawcza \$x język litewski

Utworzone powiązanie reprezentuje relację porównywania dwóch przedmiotów i powinno zawierać dwie role typu „przedmiot porównywany”. Dodatkowo można dodać zakres wskazujący problematykę, z punktu widzenia której są rozpatrywane języki, w tym przypadku będzie to gramatyka. Nie jest to jednak konieczne, ponieważ zakres można również ustanowić między zreifikowanym tematem a wystąpieniem lub tematem reprezentującym zasób informacyjny.

\section{przedmiot-porównywany/przedmiot-porównywany isa tmcl:association-type; has-role(przedmiot-porównywany, 2, 2). \\ przedmiot-porównywany/przedmiot-porównywany(przedmiot-porównywany: język-polski, przedmiot-porównywany: język-litewski).}

Kolejnym przykładem jest określnik „dzieła”, który jest zawsze uzupełniany drugim określnikiem rzeczowym identyfikującym konkretną dziedzinę twórczości. Reprezentuje on relację między osobą a dziedziną działalności. Nie jest to związek symetryczny. Pierwszy człon relacji reprezentuje temat identyfikujący konkretną osobę, a drugi - określnik identyfikujący dziedzinę twórczości. W rekordzie wzorcowym określnika „dzieła” zaznaczono, że musi to być dziedzina niebędąca główną sferą działalności danej osoby. Schemat opisu zawiera jedno obowiązkowe hasło. Został zaprezentowany poniżej wraz z przykładem zastosowania.

$a R b \quad 600$ 1\# \$a Wyczótkowski, Leon \$d (1852-1936) \$x dzieła \$x grafika

Relację identyfikowaną przez hasło rozwinięte z określnikiem „dzieła” można przedstawić jako powiązanie typu „osoba/dziedzina-działalności”. Ograniczenie dotyczące tego typu powiązania wraz z przykładem wykorzystania przedstawiono poniżej za pomocą konwencji TMCL.

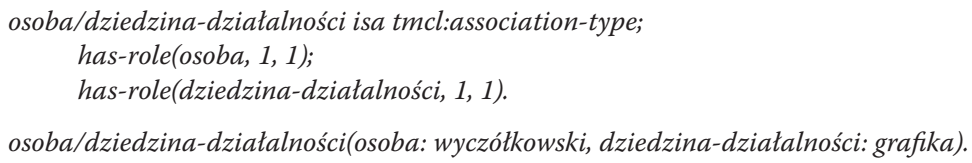

Wśród wariantów nazw określników o budowie „dzieła - [dziedzina]” znajdują się nazwy o konstrukcji „wkład do [dziedziny]”. Warianty te są równokształtne z określnikami występującymi w KABA. Różnica w budowie polega na tym, że określnik ten identyfikuje zarówno rodzaj relacji, jak i jej drugi człon. W związku z tym w znajdującym się poniżej schemacie drugi argument relacji został zapisany w nawiasie okrągłym. Pod schematem zamieszczono również przykład zastosowania określnika i powiązanie powstałe w wyniku jego przekształcenia.

aR(b) $600 \quad 1 \# \quad \$ a$ Pol, Wincenty \$d (1807-1872) \$x wktad do archeologii

osoba/dziedzina-działalności(osoba: pol, dziedzina-działalności: archeologia).

Kolejny przykład dotyczy całej grupy określników o budowie „wpływ [przymiotnik od nazwy cywilizacji, religii, obszaru geograficznego, grupy etnicznej]”. Służą one do wskazania 
wpływu wymienionych w nawiasie kwadratowym kategorii przedmiotów na grupy etniczne oraz przedmioty z zakresu sztuki, kultury, literatury i cywilizacji. Są to relacje asymetryczne, czyli zachodzą tylko w jednym kierunku. W części przypadków oba człony relacji znajdują się w obrębie jednego hasła rozwiniętego.

$a R(b) \quad 650$ \#\# \$a Literatura niemiecka \$x wptyw amerykański.

Powyższe hasło można odczytać jako wpływ Stanów Zjednoczonych na literaturę niemiecką. W takich przypadkach drugi człon relacji często nie jest precyzyjnie prezentowany w opisie. W podanym przykładzie może bowiem chodzić o wpływ kultury amerykańskiej na literaturę niemiecką. W opisie brakuje jednak hasła identyfikującego kulturę amerykańską. Niekiedy argumenty takiej relacji mogą występować w opisie jako osobne tematy uzupełnione określnikami. Poniżej zaprezentowano schemat opisu i przykład jego wykorzystania zaczerpnięty z katalogu NUKAT. Oznaczenie „x” identyfikuje elementy nie wchodzące w skład relacji.

ax 650 \#\# \$a Literatura amerykańska \$x wptyw.

$b R(x) \quad 650$ \#\# \$a Literatura angielska \$x wptyw amerykański.

Do reprezentacji tego rodzaju relacji w mapie tematów może służyć powiązanie składające się z dwóch typów ról: „przedmiot-wpływający” i „przedmiot-na-który-wywierany-jest-wpływ":

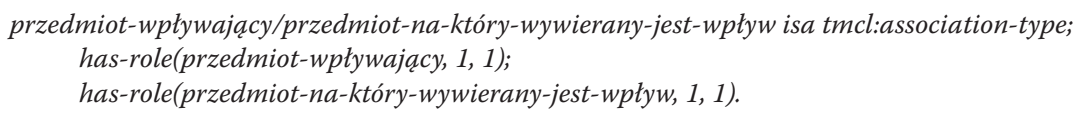

przedmiot-wptywający/przedmiot-na-który-wywierany-jest-wptyw(przedmiot-wptywający: literatura-amerykańska, przedmiot-na-który-wywierany-jest-wptyw: literatura-angielska).

Wspomniany już schemat „aR(b)” występuje też w wielu innych hasłach, m.in. zawierających określniki o konstrukcji „skutki oddziaływania [przedmiotu]”. Poniżej zaprezentowano przykład hasła z jednym z określników należących do tej grupy.

650 \#\# \$a Śliwa domowa \$x skutki oddziatywania wapnia.

Hasło o takiej budowie również można przekształcić zgodnie z przedstawionym powyżej wzorem.

Inny schemat występuje w przypadku opisów zawierających określnik „deportacje z [nazwa kraju lub regionu większego niż kraj]”. Zaprezentowano go poniżej wraz z przykładem użycia.

$$
\begin{aligned}
& x a \quad 650 \text { \#\# \$a Deportacja \$z Zwiazek Radziecki \$y 1900-1945. } \\
& x R(b) 650 \text { \#\# \$a Wojna światowa (1939-1945) \$x deportacje z Litwy. }
\end{aligned}
$$

W mapie tematów powyższą relację można przedstawić zgodnie z zaprezentowanym schematem:

państwo-źródłowe-deportacji/państwo-docelowe-deportacji isa tmcl:association-type; has-role(państwo-źródtowe-deportacji, 1, 1); has-role(państwo-docelowe-deportacji, 1, 1). 
państwo-źródłowe-deportacji/państwo-docelowe-deportacji(państwo-źródłowe-deportacji: litwa, państwo-docelowe-deportacji: zwiazek-radziecki).

Schemat podobny do przedstawionego powyżej obowiązuje w opisach z określnikiem „więźniowie i więzienia [nazwa narodowości]”. Różnica dotyczy drugiego elementu relacji, który nie jest reprezentowany przez określnik, ale przez temat.

$x R(a) 650$ \#\# \$a Wojna światowa (1939-1945) \$x więźniowie i więzienia Niemców.

bx 650 \#\# \$a Więźniowie polityczni polscy \$z Litwa \$z Wilno \$y 1900-1945.

Relacja ponownie zachodzi między dwoma przedmiotami, które odgrywają odmienne role.

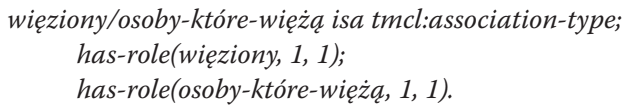

Na relację między przedmiotami wskazują także określniki o konstrukcji „w [medium]”. Identyfikują one relację przedstawienia przedmiotu m.in. w filmie, teatrze oraz literaturze. Schemat opisu z zastosowaniem tych określników obejmuje jedno lub dwa hasła. Poniżej został podany pierwszy z nich wraz z przykładem zastosowania.

aR(b) 650 \#\# \$a Sacrum \$xw kinie

W drugim schemacie występują dwa hasła.

ax 650 \#\# \$a Kino polskie \$x tematy, motywy.

$b R(x) 650$ \#\# \$a Sity zbrojne \$xw kinie.

Ten opis przedmiotowy można przedstawić z wykorzystaniem typu powiązania „przedmiot/medium".

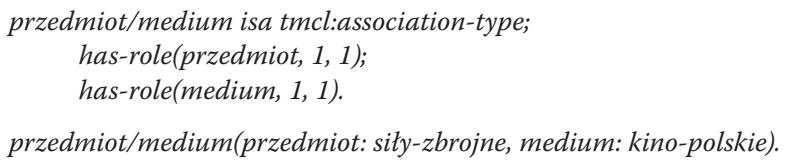

przedmiot/medium(przedmiot: sity-zbrojne, medium: kino-polskie).

Sytuację komplikuje nieco występowanie określników rzeczowych takich jak np. „kino i wojna”. Zgodnie z notą zapisaną w rekordzie wzorcowym, określnik ten „stosuje się po nazwach wojen do prac omawiających sytuację kina w okresie danej wojny, jak również do prac na temat tej wojny w produkcji filmowej współczesnej danej wojnie lub późniejszej”. Jest to jeden z określników, które identyfikują jednocześnie kilka rodzajów związków między przedmiotami. Nie można wyodrębnić w sposób automatyczny szczegółowych relacji między przedmiotami z haseł zawierających te określniki. Poniżej zaprezentowano schemat i przykład opisu dokumentu na temat przedstawienia II wojny światowej w filmie amerykańskim.

ax 650 \#\# \$a Kino amerykańskie \$x tematy, motywy.

bR 650 \#\# \$a Wojna światowa (1939-1945) \$x kino i wojna. 
Zaprezentowany powyżej opis można przedstawić z wykorzystaniem powiązania „przedmiot/medium".

Kolejną jednostką identyfikującą jednocześnie kilka rodzajów związków między przedmiotami jest określnik „i [...]”, występujący w dwóch wariantach: „i [przedmiot]” oraz „i [jednostka geograficzna]”. Pierwszy z wariantów jest stosowany „po nazwach osobowych, nazwach rodów i rodzin oraz po nazwach odpowiednich instytucji i organizacji (partii politycznych, związków zawodowych, itp.), w odniesieniu do prac na temat ich postaw, opinii lub znajomości danego przedmiotu określonego wyłącznie nazwą pospolitą”, drugi zaś „do prac na temat ich postawy, opinii i znajomości danego obszaru (miasta, kraju lub regionu większego niż kraj)”. Próba wyodrębnienia bardziej szczegółowych związków między przedmiotami jest w tym przypadku utrudniona, ponieważ znaczenie określnika „i [...]” jest odmienne w różnych opisach przedmiotowych. W rekordach wzorcowych języka KABA zapisywane są odpowiedniki jednostek leksykalnych z RAMEAU oraz LCSH. Określnik KABA „, [ [...]” jest skonstruowany analogicznie jak jego odpowiednik w RAMEAU. W LCSH występuje pięć odpowiedników tego określnika wskazujących na trzy rodzaje relacji:

(1) „Knowledge \$x [specific topic]” (znajomość danego przedmiotu),

(2) „Relations with [specific class of persons or ethnic group]” (relacje z określoną kategorią osób lub grupą etniczną),

(3) „Views on [specific topic]” (opinia o danym przedmiocie),

(4) „Knowledge \$x [America, etc]” (znajomość danego obszaru) oraz

(5) „Views on \$x [America, etc]” (opinia o danym obszarze).

Rozwiązanie przyjęte w BK ułatwia ewentualne przekształcenie LCSH w mapę tematów. Poniżej zamieszczono schemat zawierający określnik „i [...]” oraz przykład fragmentu opisu przedmiotowego zgodnego z językiem KABA. Podano również jego odpowiednik w LCSH.

Modernist poetics of history: Pound, Eliot, and the sense of the past / James Longenbach. Princeton, cop. 1987.

Hasło przedmiotowe KABA:

aR(b) 600 1\# \$a Eliot, Thomas Stearns \$d (1888-1965) \$x i historia.

Hasło przedmiotowe LCSH:

$60010 \$$ a Eliot, T. S. \$q (Thomas Stearns), \$d 1888-1965 \$x Knowledge \$x History.

Jedynie opis sporządzony z użyciem LCSH umożliwia automatyczne utworzenie dokładnego powiązania oddającego treść dokumentu. W przypadku opisu w KABA należy utworzyć bardziej ogólny typ powiązania lub przeanalizować opisy przedmiotowe zawierające określnik „i [...]”:

osoba/dziedzina-poznania isa tmcl:association-type;

has-role(osoba, 1, 1);

has-role(dziedzina-poznania, 1, 1).

osoba/dziedzina-poznania(osoba: eliot, dziedzina-poznania: historia).

W KABA występują również tematy o konstrukcji „[przedmiot] i [przedmiot]”, wskazujące relacje między przedmiotami. Ich przekształcenie byłoby podobne jak w przypadku 
haseł rozwiniętych z określnikiem „i [...]”. Tematy takie mogą identyfikować różne rodzaje relacji między przedmiotami.

Innym określnikiem wskazującym różne relacje jest określnik „aspekt społeczny”. Zastosowany po temacie „Wojna” lub temacie nazywającym konkretny konflikt zbrojny, może identyfikować zarówno sytuację społeczną w czasie wojny, jak i wpływ wojny na społeczeństwo lub społeczeństwa na wojnę (Ćwikowski, 2013, 61). Brak jawnego wyodrębnienia tych znaczeń ponownie utrudnia przekształcenie.

Tabela 1 prezentuje wykaz określników KABA identyfikujących relacje między przedmiotami, uporządkowanych zgodnie z wyodrębnionymi wcześniej schematami.

Tabela 1. Podział określników rzeczowych KABA wskazujących relacje między przedmiotami zgodnie ze schematami ich użycia w opisach przedmiotowych

\begin{tabular}{|c|c|c|c|c|}
\hline $\begin{array}{c}\text { Schemat } \\
\text { zastosowania }\end{array}$ & \multicolumn{4}{|c|}{ Określniki rzeczowe wskazujące relacje między przedmiotami } \\
\hline 1 & 2 & 3 & 4 & 5 \\
\hline \multirow{2}{*}{$\begin{array}{l}\mathrm{aRb} \\
\mathrm{bRa}\end{array}$} & $\begin{array}{c}\text { fonologia } \\
\text { porównawcza }\end{array}$ & $\begin{array}{c}\text { gramatyka } \\
\text { porównawcza }\end{array}$ & stosunki & $\begin{array}{c}\text { stosunki } \\
\text { gospodarcze } \\
\text { z zagranicą }\end{array}$ \\
\hline & $\begin{array}{l}\text { stosunki } \\
\text { wojskowe }\end{array}$ & $\begin{array}{c}\text { stosunki } \\
\text { zagraniczne }\end{array}$ & & \\
\hline $\mathrm{aRb}$ & $\begin{array}{c}\text { dzieła - } \\
\text { [dziedzina] }\end{array}$ & $\begin{array}{c}\text { kariera - } \\
\text { [dziedzina] }\end{array}$ & $\begin{array}{c}\text { rola - } \\
\text { [nazwa postaci] }\end{array}$ & $\begin{array}{l}\text { studia i naucza- } \\
\text { nie - [grupa osób } \\
\text { posługujących się } \\
\text { określonym języ- } \\
\text { kiem/dziedzina] }\end{array}$ \\
\hline \multirow{4}{*}{$\mathrm{aR}(\mathrm{b})$} & aspekt społeczny & $\begin{array}{l}\mathrm{i} \text { [przedmiot / } \\
\text { nazwa } \\
\text { geograficzna] }\end{array}$ & $\begin{array}{l}\text { konsumpcja } \\
\text { alkoholu }\end{array}$ & $\begin{array}{l}\text { konsumpcja } \\
\text { energii }\end{array}$ \\
\hline & $\begin{array}{l}\text { odkrycia i bada- } \\
\text { nia [przymiotnik } \\
\text { od nazwy narodo- } \\
\text { wości] }\end{array}$ & $\begin{array}{l}\text { odporność na } \\
\text { [przedmiot] }\end{array}$ & $\begin{array}{l}\text { opinia publiczna } \\
\text { [przymiotnik } \\
\text { od nazwy } \\
\text { geograficznej] }\end{array}$ & $\begin{array}{c}\text { [przedmiot] } \\
\mathrm{i} \text { [powstanie / } \\
\text { rewolucja / } \\
\text { wojna] }\end{array}$ \\
\hline & $\begin{array}{c}\text { relacja do [księga } \\
\text { święta] }\end{array}$ & $\begin{array}{c}\text { roszczenia wobec } \\
\text { [państwo] }\end{array}$ & $\begin{array}{l}\text { skutki oddziały- } \\
\text { wania } \\
\text { [przedmiotu] }\end{array}$ & $\begin{array}{c}\text { studia i nauczanie } \\
\text { [szczebel } \\
\text { kształcenia] }\end{array}$ \\
\hline & $\begin{array}{c}\text { transliteracja } \\
\text { [przymiotnik } \\
\text { od nazwy języka] }\end{array}$ & $\begin{array}{c}\text { udział [nazwa } \\
\text { grupy etnicznej / } \\
\text { nazwa kategorii } \\
\text { osób / przymiot- } \\
\text { nik od nazwy } \\
\text { geograficznej } \\
\text { lub nazwy } \\
\text { narodowości] }\end{array}$ & $\mathrm{w}$ [medium] & $\begin{array}{l}\text { wpływ [przymiot- } \\
\text { nik od nazwy } \\
\text { cywilizacji / } \\
\text { religii / obszaru } \\
\text { geograficznego / } \\
\text { grupy etnicznej] }\end{array}$ \\
\hline
\end{tabular}




\begin{tabular}{|c|c|c|c|c|}
\hline 1 & 2 & 3 & 4 & 5 \\
\hline \multirow{3}{*}{$\mathrm{aR}(\mathrm{b})$} & $\begin{array}{l}\text { wkład do } \\
\text { [dziedziny] }\end{array}$ & $\begin{array}{c}\text { wpływ } \\
\text { na człowieka }\end{array}$ & $\begin{array}{c}\text { wpływ na [nazwa } \\
\text { dialektu / nazwa } \\
\text { języka] }\end{array}$ & $\begin{array}{c}\text { wpływy } \\
\text { z kosmosu }\end{array}$ \\
\hline & $\begin{array}{l}\text { wykorzystanie } \\
\text { [przymiotnik } \\
\text { od nazwy } \\
\text { przedmiotu] }\end{array}$ & $\begin{array}{l}\text { wykorzystanie } \\
\text { dla celów } \\
\text { [przymiotnik } \\
\text { od nazwy } \\
\text { przedmiotu] }\end{array}$ & $\begin{array}{c}\text { zależność } \\
\text { od [nazwa } \\
\text { geograficzna] }\end{array}$ & $\begin{array}{c}\text { zapotrzebowanie } \\
\text { na wodę }\end{array}$ \\
\hline & $\begin{array}{c}\text { zapożyczenia } \\
\text { [przymiotnik } \\
\text { od nazwy języka] }\end{array}$ & $\begin{array}{c}\text { zastosowanie } \\
\mathrm{w} \text { [przedmiocie] }\end{array}$ & $\begin{array}{c}\text { zawartość [nazwa } \\
\text { substancji / naz- } \\
\text { wa grup } \\
\text { substancji] }\end{array}$ & \\
\hline $\begin{array}{c}\text { ax } \\
\mathrm{bR}(\mathrm{x})\end{array}$ & $\begin{array}{l}\text { wpływ [przymiot- } \\
\text { nik od nazwy } \\
\text { cywilizacji / } \\
\text { religii / obszaru } \\
\text { geograficznego / } \\
\text { grupy etnicznej] }\end{array}$ & $\mathrm{w}$ [medium] & $\begin{array}{l}\text { udział [nazwa } \\
\text { grupy etnicznej / } \\
\text { nazwa kategorii } \\
\text { osób / przymiot- } \\
\text { nik od nazwy } \\
\text { geograficznej } \\
\text { lub nazwy } \\
\text { narodowości] }\end{array}$ & \\
\hline $\begin{array}{c}x a \\
x R(b)\end{array}$ & $\begin{array}{c}\text { deportacje } \\
\text { z [konkretnej } \\
\text { jednostki } \\
\text { geograficznej] }\end{array}$ & & & \\
\hline $\begin{array}{c}\mathrm{xR}(\mathrm{a}) \\
\mathrm{bx}\end{array}$ & $\begin{array}{c}\text { więźniowie } \\
\text { i więzienia [na- } \\
\text { zwa narodowości] }\end{array}$ & & & \\
\hline $\begin{array}{l}\text { ax } \\
\text { bR }\end{array}$ & $\begin{array}{l}\text { [przedmiot] } \\
\mathrm{i} \text { [powstanie / re- } \\
\text { wolucja / wojna] }\end{array}$ & & & \\
\hline
\end{tabular}

Źródło: opracowanie własne.

\section{Kontrola typów ról i tematów w mapie tematów opartej na języku $\mathrm{KABA}$}

W tej części artykułu przedstawiono ograniczenia dotyczące instancji poszczególnych typów tematów i ról, w jakich mogą one występować w powiązaniach. Odwołano się do przykładów wcześniej zaprezentowanych w tekście. Pierwszy z przykładów zawierał dwa hasła z określnikiem „stosunki wojskowe”. W nawiasach ostrokątnych podano kategorie z listy KABA, do której należą argumenty relacji. 
Wykorzystując te informacje, można stworzyć ograniczenie wskazujące, że instancje typu tematu „Jednostki geograficzne” (nazwy geograficzne) mogą, ale nie muszą, odgrywać dowolną liczbę ról typu „państwo-pozostające-w-stosunkach-wojskowych” w powiązaniach typu „państwo-pozostające-w-stosunkach-wojskowych/państwo-pozostające-w-stosunkach-wojskowych":

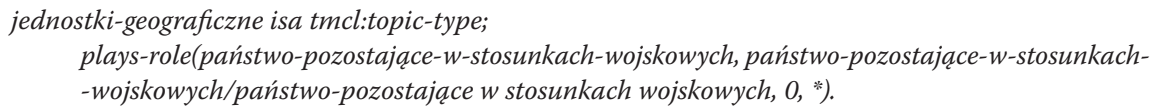

W JHP KABA określnik „stosunki wojskowe” jest stosowany po nazwach państw i regionów większych. W mapie tematów można zapisać, że tematy występujące w powiązaniu reprezentującym stosunki wojskowe powinny należeć do typów: „Państwa” lub „Regiony”. Wymaga to ich wyodrębnienia z ogólniejszej kategorii tematów reprezentujących jednostki geograficzne.

Podobnie można postąpić w drugim przypadku (z określnikiem „gramatyka porównawcza").

$<j e ̨ z k i>$ gramatyka porównawcza $<j e ̨ z y k i>$

Wykorzystując zaprezentowane informacje można utworzyć następujące ograniczenie: języki isa tmcl:topic-type; plays-role(przedmiot-porównywany, przedmiot-porównywany/przedmiot-porównywany, 0, *).

Kolejny określnik - „dzieła”, łączy osobę z dziedziną działalności. Na zaprezentowanej w pierwszej części artykułu liście brakuje odpowiedniej kategorii odpowiadającej drugiemu elementowi relacji. Najpierw została ona zapisana jako „Przedmioty”, czyli najogólniejsza kategoria gromadząca wszystkie przedmioty. W nawiasie klamrowym została przedstawiona propozycja bardziej szczegółowej kategorii.

$<$ nazwy osobowe $>$ dzieła $<$ przedmioty $>\{d z i e d z i n y\}$

Ograniczenia dotyczą w tym przypadku dwóch typów tematów, które mogą grać w omawianym typie powiązania dwie osobne role.

osoby isa tmcl:topic-type;

plays-role(osoba, osoba/dziedzina-dziatalności, $\left.0,{ }^{*}\right)$.

dziedziny isa tmcl:topic-type;

plays-role(dziedzina-działalności, osoba/dziedzina-działalności, 0, *).

Tę samą relację identyfikuje również hasło o innej budowie:

$<$ nazwy osobowe $>$ wktad do $<$ przedmioty $>\{d z i e d z i n y\}$

Podczas jego przekształcenia można zastosować ograniczenia przedstawione powyżej. W przypadku bardziej złożonej transformacji hasła z określnikiem „wpływ [...]”, wśród kategorii zamieszczonych na liście określników, również brakuje odpowiedniej nazwy wskazującej grupę przedmiotów.

$<$ przedmioty $>$ \{przedmioty-z-dziedziny-sztuki-kultury-literatury\} wptyw $<$ przedmioty $>\{$ przedmioty-

-z-dziedziny-sztuki-kultury-literatury\} 
Zapis TMCL wskazuje, że w powiązaniu „przedmiot-wpływający/przedmiot-na-który-wywierany-jest-wpływ” role odgrywają tematy należące do typu „Przedmioty z dziedziny sztuki, kultury i literatury".

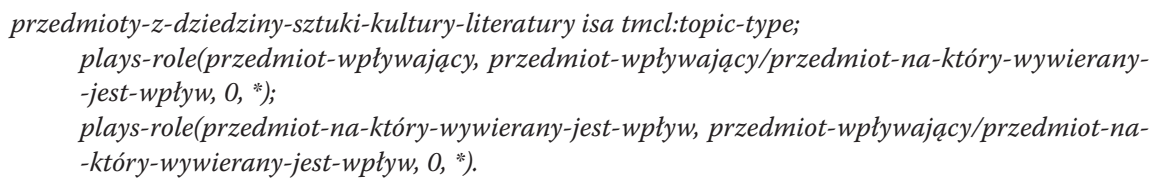

Powyżej podano jedynie przykład jednego z możliwych ograniczeń. Na inne możliwości zapisu wskazuje nota stosowania określnika „wpływ [przymiotnik od nazwy cywilizacji, religii, obszaru geograficznego, grupy etnicznej]”. W powiązaniu tego typu mogą występować wspólnie tematy należące do wielu typów.

Relację wpływu identyfikują także inne określniki o konstrukcji „skutki oddziaływania [przedmiotu]”. Podobnie jak w przypadku określnika „wpływ [przymiotnik od nazwy cywilizacji, religii, obszaru geograficznego, grupy etnicznej]", pierwszy argument relacji może należeć do różnych kategorii, na co wskazuje nota stosowania określnika. W tym miejscu pokazano jedynie przykładowe zestawienie typów tematów:

<organizmy żywe> skutki oddziatywania < substancje chemiczne>

Poniższe ograniczenia odnoszą się do przedstawionego przykładu.

organizmy-żywe isa tmcl:topic-type;

plays-role(przedmiot-na-który-wywierany-jest-wptyw, przedmiot-wptywajacy/przedmiot-na-

-który-wywierany-jest-wptyw, 0, *).

substancje-chemiczne isa tmcl:topic-type;

plays-role(przedmiot-wptywający, przedmiot-wptywajacy/przedmiot-na-który-wywierany-jest-wptyw, 0 , *).

Obydwa argumenty relacji identyfikowanej przez określnik „deportacje z [nazwa kraju lub regionu większego niż kraj]” należą do tej samej kategorii. Zaprezentowano ją poniżej.

$<$ nazwy geograficzne $>$ deportacje $z<$ nazwy geograficzne $>$

W ograniczeniu występuje zatem jeden typ tematu:

jednostki-geograficzne isa tmcl:topic-type;

plays-role(państwo-źródłowe-deportacji, państwo-źródłowe-deportacji/państwo-docelowe-deportacji, 0 , *);

plays-role(państwo-docelowe-deportacji, państwo-źródłowe-deportacji/państwo-docelowe-deportacji, $0, *)$.

W kolejnym typie powiązania opartym na opisie zawierającym określnik „więźniowie i więzienia [nazwa narodowości]”, argumenty należą do odmiennych kategorii.

$<$ kategorie osób > więźniowie i więzienia < grupy etniczne>

Niezbędne są dwa ograniczenia:

kategorie-osób isa tmcl:topic-type;

plays-role(więziony, więziony/osoby-które-więżą, 0, *). 
grupy-etniczne isa tmcl:topic-type;

plays-role(osoby-które-więża, więziony/osoby-które-więża, 0, ").

Następny przykład reprezentuje relację przedstawienia przedmiotu w medium. Na dziedzinowych listach określników ponownie brakuje odpowiedniej kategorii. W nawiasie klamrowym zaproponowano szczegółową propozycję.

$<$ przedmioty $>w<$ przedmioty $>\{$ media $\}$

W różnych mediach mogą być prezentowane rozmaite przedmioty, co uwzględniono w notach stosowania takich określników jak „w kinie”. Niezbędne są dwa ograniczenia odnoszące do dwóch typów tematów:

przedmioty isa tmcl:topic-type;

plays-role(przedmiot, przedmiot/medium, 0 , *).

media isa tmcl:topic-type;

plays-role(medium, przedmiot/medium, 0 , *).

W poprzedniej części artykułu wskazano, że określnik „i [...]” może identyfikować różne rodzaje relacji, które w przeciwieństwie do LCSH nie są rozróżniane w KABA. Bez analizy znaczenia tych połączeń nie można określić szczegółowego rodzaju powiązania w mapie tematów.

$<$ osoby $>i<$ przedmioty $>\{d z i e d z i n y\}$

Ograniczenia prezentują wariant, w którym wyróżniono szczegółowy rodzaj powiązania - relację między osobą a dziedziną poznania, przedstawiającą znajomość dziedziny przez daną osobę.

osoby isa tmcl:topic-type;

plays-role(osoba, osoba/dziedzina-poznania, 0 , *).

dziedziny isa tmcl:topic-type;

plays-role(dziedzina-poznania, osoba/dziedzina-poznania, 0 , *).

\section{Zakończenie}

W artykule przedstawiono możliwości i problemy przekształcenia wybranych relacji, występujących w pojedynczych hasłach rozwiniętych KABA i całych opisach przedmiotowych do postaci powiązań w mapie tematów. W JHP KABA, oprócz podziału tematów i określników zgodnego z etykietami pól formatu MARC 21, dokonano kategoryzacji określników w celu kontroli połączeń między jednostkami leksykalnymi w hasłach rozwiniętych. Dane na ten temat są zapisane w rekordach wzorcowych określników (pole 073). Brakuje ich jednak w rekordach wzorcowych tematów (pole 072), co uniemożliwia automatyczną kontrolę poprawności haseł rozwiniętych. Pokazano, że uzupełnienie tych informacji tylko w ograniczonym zakresie może być pomocne przy przekształceniu języka do postaci mapy tematów. W przypadku niektórych jednostek identyfikujących argumenty relacji konieczne było zaproponowanie dodatkowych kategorii, które pozwoliły na zapis ograniczeń dotyczących powiązań. Wydzielono m.in. typy tematów „Dziedziny” i „Media”. Podczas tworzenia systemu organizacji wiedzy powinno się zwracać uwagę na możliwości 
jego formalizacji, czyli opisu łączliwości jednostek leksykalnych i zasad pragmatycznych w sposób umożliwiający automatyczny nadzór nad tworzonymi charakterystykami wyszukiwawczymi. W języku KABA nie dokończono tego procesu.

W artykule zaprezentowano przykłady przekształcenia wybranych haseł i opisów przedmiotowych do postaci powiązań w mapie tematów. Kryterium doboru było występowanie w ich składzie określników rzeczowych reprezentujących relacje między przedmiotami. Podział całości zasobu leksykalnego KABA byłby dużo bardziej złożony i wymagałby utworzenia licznych ograniczeń. Zalecane byłoby przynajmniej częściowe zautomatyzowanie tej pracy.

Przedstawione rozwiązanie cechuje się większymi możliwościami wielowymiarowego opisu treści dokumentów w porównaniu z przekształceniami JHP odwołującymi się do tradycyjnych języków deskryptorowych. Dzięki zachowaniu kontekstu semantycznego umożliwia ono opracowanie rzeczowe zarówno za pomocą pojedynczych tematów, jak i tematów połączonych określonymi powiązaniami. W systemie opartym na mapie tematów, zapytania mogłyby być konstruowane w oparciu o jawnie specyfikowane relacje między tematami zapewniając większą precyzję wyszukiwania. Dzięki zaproponowanemu rozwiązaniu, nawiązującemu do teorii indeksowania relacyjnego Jasona Farradane'a (zob. np. Chmielewska-Gorczyca, 1981), możliwe jest wykorzystanie informacji dotyczących treści i formy dokumentów zawartych w dotychczas utworzonych opisach przedmiotowych.

\section{Bibliografia}

BnF (2016). Guide d'indexation RAMEAU [online]. Bibliothèque nationale de France, [07.07.2016], http://guiderameau.bnf.fr

Cichoń, M.; Kalinowski, J.; Federowicz, G.(2014). Katalogowanie oparte na encjach. Rocznik Biblioteki Narodowej, 45, 151-200.

Chmielewska-Gorczyca, E. (1981). Metoda indeksowania relacyjnego Farradane'a. Zagadnienia Informacji Naukowej, 38(1), 83-97.

Ćwikowski, P. (2013). Opis przedmiotowy dokumentów na temat wojen i wojskowości. Warszawa: Wydaw. SBP.

ISO (2006). ISO/IEC 13250-2:2006. Information technology - Topic Maps - Part 2: Data model.

ISO (2011). ISO/IEC 19756:2011. Information technology - Topic Maps - Constraint Language (TMCL). Język deskryptorowy (2002). W: Stownik encyklopedyczny informacji, języków i systemów informacyjno-wyszukiwawczych. Warszawa: Wydaw. SBP, 102.

LoC (b.d.). Library of Congress Authorities [online]. Library of Congress, [07.07.2016], http://authorities.loc.gov/

LoC (1999). 073 - Subdivision Usage (NR) [online]. Library of Congress, [07.07.2016], https://www. loc.gov/marc/authority/ad073.html

LoC (2012). Library of Congress to Add Subject Category Codes to Selected Subject Authority Records [online]. Library of Congress, [07.07.2016], http://loc.gov/catdir/cpso/field_072_announcement.pdf

LoC (2016). Free-floating Subdivisions [online]. Library of Congress, [07.07.2016], https://www.loc. gov/aba/publications/FreeLCSH/SUBDIVISIONS.pdf

NUKAT-a (b.d.). Katalog NUKAT [online]. Centrum NUKAT, [07.07.2016], http://katalog.nukat. edu.pl/search/query?theme=nukat

NUKAT-b (b.d.). Listy dziedzinowe określników KABA [online]. Centrum NUKAT, [07.07.2016], http://centrum.nukat.edu.pl/pl/warsztat/slownictwo-jhp-kaba?view=okreslniki

NUKAT-c (b.d.). Listy dziedzinowe określników KABA - rzeczowe [online]. Centrum NUKAT, [07.07.2016], http://centrum.nukat.edu.pl/pl/warsztat/slownictwo-jhp-kaba?view=okreslniki\&layout=rzeczowe 
Włodarczyk, B. (2016). Mapy tematów jako podstawa semantyzacji języka haseł przedmiotowych. Warszawa: Wydaw. SBP.

\title{
The Transformation of Relationships in KABA Subject Heading Strings into Associations in Topic Maps
}

\begin{abstract}
Purpose/Thesis: The purpose of the paper is to present the transformation of selected KABA subject heading strings into associations in topic maps.

Approach/Research methods: The possibility of introducing more detailed categorization of KABA Subject Headings was assessed based on the documentation published by the NUKAT Center. The analysis of the scope notes of KABA topical subdivisions was used to present the types of constructions occurring in the system and the options of their transformation into associations in topic maps. Results and conclusions: KABA Subject Headings subdivision authority records already are had been populated with categories ( 073 field).However, the authority records for subject headings lack these data (expected to appear in field 072) and consequently the automatic heading string validation is impossible. Yet the addition of the categories can be helpful in transforming subject headings into topic map only to a limited extent. There is a need to create additional categories which enable the creation of constraints on topic map ontology. The paper presents examples of the transformation of selected subject heading strings. The selected strings had to include subdivisions representing relationships between subjects. The division of the whole vocabulary would be far more difficult and requiring numerous constraints. It would be advisable to automate this process, at least some of its aspects. Originality/Value: The author puts forward the proposal to transform the relationships within KABA subject heading strings into associations in topic maps. There has not been any similar analysis recorded in library and information science literature before. Owing to the compatibility of KABA, RAMEAU and LCSH systems, the results of the research can be at least partly applied in the transformation of those tools.
\end{abstract}

\section{Keywords}

KABA Subject Headings. Relationships. Subject heading strings. Topic Maps.

Dr BARTŁOMIEJ WŁODARCZYK - adiunkt w Katedrze Bibliografii i Dokumentacji na Wydziale Dziennikarstwa, Infromacji i Bibliologii Uniwersytetu Warszawskiego. Jego zainteresowania badawcze dotycza problematyki organizacji informacji i wiedzy. Najważniejsze publikacje: B. Wtodarczyk: Mapy tematów jako podstawa semantyzacji języka haset przedmiotowych. Warszawa 2016; B. Wtodarczyk: Deskryptory formalne $w$ Bibliotece Kongresu a tematy formalne $w$ języku haset przedmiotowych Biblioteki Narodowej $i$ w języku KABA. Przeglad Biblioteczny 2014, 4, 518-536; B. Wtodarczyk: Topic Map as a Method for the Development of Subject Headings Vocabulary: An Introduction to the Project of the National Library of Poland. Cataloging \& Classification Quarterly 2013, 7, 816-829.

Kontakt $z$ autorem:

bm.wlodarczyk@uw.edu.pl

Katedra Bibliografii i Dokumentacji

Wydziat Dziennikarstwa, Informacji i Bibliologii

Uniwersytet Warszawski

ul. Nowy Świat 69

00-927 Warszawa 